\title{
Marine-like isopod Heterosphaeroma priscum from the Late Paleocene freshwater system in Sézanne, France, revisited
}

\author{
Ninon Robin and Ronald Vonk \\ Acta Palaeontologica Polonica 65 (4), 2020: $793-798$ doi:https://doi.org/10.4202/app.00767.2020
}

Well-known for its Palaeocene terrestrial flora, the travertine deposit of Sézanne (Marne, Champagne, France) has also yielded a small number of well-preserved crustaceans, including isopods. In 1868, a single specimen of these isopods has been described by the French zoologist Alphonse Milne-Edwards who remarked on its resemblance to the common benthic isopods from the marine littoral (Sphaeromatidae). A few years later, more material of that same species from Sézanne allowed Charles P.E. Munier- Chalmas to place it in his new genus Heterosphaeroma, but without figuring the species or proposing many diagnostic features. Recently, more material of this species turned up in the Sorbonne collection allowing for a more complete description. Here, we provide a redescription of the Sézanne isopod species based on rediscovered original material. Systematic features are discussed that confirm its sphaeromid affinity. In light of recent knowledge on incursions of the Thanetian Sea in this area, and associated travertine palaeofauna and flora, we assume a high likelihood for this species to have lived in karstic spring waters and freshwater calcareous streams during the end of the Palaeocene. We finally discuss the ability of some Recent sphaeromatids to live in freshwater conditions, deep inland, and we compare their ecology to those found in the Paris Basin travertine palaeoenvironments.

Ninon Robin [ninonrobin23@gmail.com], School of Biological, Earth \& Environmental Sciences, University College Cork, Butler Building, North Mall, T23 TK3 Cork, Ireland. Ronald Vonk [ronald.vonk@naturalis.nl] (corresponding author), Naturalis Biodiversity Center, P.O. Box 9517, 2300 RA Leiden, The Netherlands; Institute for Biodiversity and Ecosystem Dynamics, University of Amsterdam, P.O. Box 94248, 1090 GE Amsterdam, The Netherlands.

This is an open-access article distributed under the terms of the Creative Commons Attribution License (for details please see creativecommons.org), which permits unrestricted use, distribution, and reproduction in any medium, provided the original author and source are credited. 
Forf Full text $(1,316.8 \mathrm{kB})$ 